\title{
Design and Construction of an Improved Balancing Machine
}

\author{
Patrick Adebisi Olusegun Adegbuyi, Fadipe Opeyemi Lukuman
}

Department of Mechanical Engineering, Lagos State University, Lagos, Nigeria

\author{
Email address: \\ paorene011@yahoo.com (P.A. O. Adegbuyi)
}

\section{To cite this article:}

Patrick Adebisi Olusegun Adegbuyi, Fadipe Opeyemi Lukuman. Design and Construction of an Improved Balancing Machine. International Journal of Science, Technology and Society. Vol. 5, No. 3, 2017, pp. 41-45. doi: 10.11648/j.ijsts.20170503.13

Received: March 2, 2017; Accepted: April 14, 2017; Published: May 25, 2017

\begin{abstract}
The balancing machine is equipment used for the following- determining the proper location and amount of balance work in a rotor (applicable in a motor amerture) - determining the position and magnitude of a given mass to balance the unbalance centrifugal effect of a system (this is applicable in determining automobile crankshaft mass distribution. This equipment was designed and constructed for the use of the Faculty Engineering, Lagos State University the Mechanics of Machine Laboratory since the possibility of acquiring one is remote due to the non-availability of the hard currency needed. Moreover the need to take students outside the university to use the equipment has totally been eliminated thereby saving valuable time and cost. The objective of looking inwards towards technology acquisition is also manifested.
\end{abstract}

Keywords: Design, Mass Distribution, Technology, Acquisition

\section{Introduction}

The word balance is derived from the Latin word "BILANX" which means two pans, it is often used interchangeably with scales, however, balances are the preferred terms for the instruments used for the precise measurement of small weights as masses in amounts ranging from micrograms up to a few kilograms and are differentiated according to design, weighing principles and morphological criteria (McQueary, 1973) Balancing is therefore a procedure by which the mass distribution of a rotor is checked and if necessary adjusted in order to ensure that the vibration of journals and forces on the bearing at a frequency corresponding to the operational speed are within specified limits. Thus a balancing machine is that which provides a measure of the unbalance that a rotor mounted on it so that once per revolution vibratory motion of the force on the bearings can be reduced if necessary. (Reining \& Desroehers, 1988). Production tolerances used in the manufacture of rotors are adjusted as closely as possible without running up the cost of manufacturing prohibitively. In general, it is more economical to produce parts which are not quite true and then and then to subject them to a balancing procedure than to produce such perfect parts that no correction is necessary. Typical examples of such machines are Crank shaft, electric armatures, turbo machinery, printing rollers centrifuges, flywheel, and gear wheels. Some common causes of irregularity during production are machining errors, cumulative assembly tolerances, distortions due to heat treatment, blow holes or inclusions in castings and material non-homogeneity. Because of these irregularities the actual axis of rotation does not coincide with one of the principal axis of inertia of the body, and variable disturbing forces are produced which results in vibrations. In order to remove these vibrations and establish proper operations, balancing becomes very necessary. The forces generated due to an unbalance are proportional to the rotating speed of the rotor squared.

Frequently, a machine already in operation will need rebalancing or a new machine when assembled at its permanent location will need balancing. In some cases, the cost of disassembly, shipping to a balancing machine, and delay, are prohibitive and the machine must be rebalanced in the field in its bearings. Although there are many possible causes of vibration in rotating equipment, this technique will deal only with that component of vibration, which occurs at running speed (frequency), and is caused by a mass unbalance in the rotor. It is only this component of vibration that can be eliminated by the addition or removal of weight from the rotor. The condition of unbalance of a rotating body may be classified as static or dynamic unbalance. In the case of static unbalance, the unbalance appears in a single axial plane while in the case of dynamic unbalance, the unbalance can be 
in different axial planes. As a result, while in rotation the two unbalanced forces form a couple, which rocks the axis of rotation and causes undesirable vibration of the rotor, mounted in its bearings.

All rotating masses have to be balanced to prevent an unwanted centric effect such as, heavy wear and tear in the bearings of an unbalanced rotating system, vibrations which usually occurs, when an unbalanced mass is rotating, bending and shear forces which results as the side effect of the unbalanced rotating system.(Redford G.D, 1966). Achieving a better balance in rotors in a primary act that involves redistribution of masses attached to the rotating body to reduce vibration arising from the centrifugal force (motor or shaft balancing). Considering a single rigid mass mounted in two supporting bearings and assume that the axis of rotation is horizontal. It can be shown that for the correct balance of such a rotor, two weights placed in different radial planes of the rotor are necessary and sufficient to balance the rotor. The vibratory motion of either bearing may be represented by the three components, the horizontal, the vertical and the axial component. The purpose of balancing at running speed of the rotor is to reduce the greatest of these three components to a practical minimum while the other two will be reduced to negligible amounts from their original magnitudes assuming that the radial component is the greatest.

The design and construction of an improved type of balancing machine was done by improved type of balancing machine was done by improving upon the welding of the attachment and the accessories units to one another thereby dividing the machine into several units, although there are two major type of balancing machines. (Mcqueary, 1973):

a) centrifugal / field balancing machine (in horizontal balancing machine).

b) gravity balancing machine (in vertical balancing machine)

The centrifugal (Horizontal) was chosen for it requires less time of construction and less expensive

\section{Design - General Considerations}

In designing the Balancing machine, it is of prime importance that consideration be given to the following features, shaft unit, frame and support unit, the wheel unit and the electric motor unit is the source of power. (Redford, 1966).

a) THE SHAFT UNIT. The Shaft was designed to meet up a specified need of the balancing machine by taking into account the adequate strength of the shaft under the most adverse loading condition because the efficiency of a machine depends on how the shaft performs its adequate rigidity, and the purpose it is used for. Mild steel is used as the construction material due to its ductility (Ryder, 1986).

b) THE WHEEL UNIT. The wheels were cast from aluminum with the shaft running through its centre. The wheels are four in numbers and fastened to the shaft by the use of keys. The construction material is steel alloy.

c) THE FRAME AND SUPPORT UNIT. This were made of cast-angle, Iron-with the support stand taking an inverted ' $U$ ' shape instead of the existing ' $L$ ' shape.

\section{Design Analysis}

This has been centered to the V-belt drive, the wheel, shaft, the motor shaft diameter, the link motion, the spring tension, and the determination of torque values at specific points in the cycle. A final assessment is also made of the functional, aesthetic and ergonomic condition of the machine (Oviawe, 1980).

\subsection{The V-belt Drive}

The need for the simplicity and economy suggest a belt drive for a separate electric motor fitted to the driven pulley. Power is transmitted to the balancing machine from a 3phase induction motor, with a speed of 1400rpm through a Texrope V-belt reduction drive.

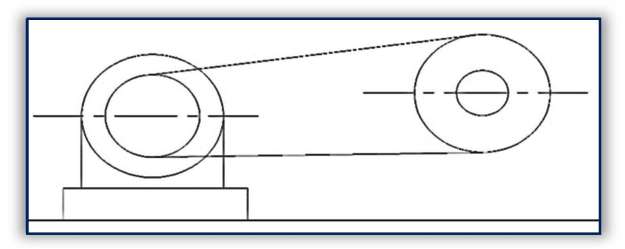

Figure 1. The Electric motor drives in connection to the flywheel.

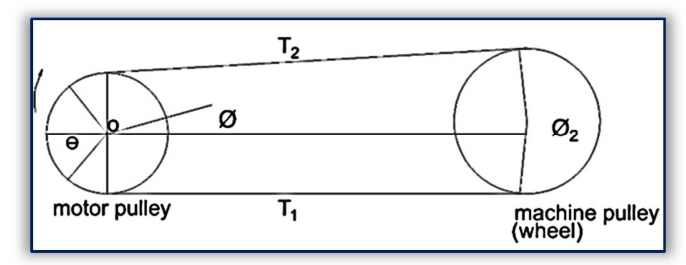

Figure 2. The Distribution of belt tension $T_{1}$ and $T_{2}$.

Let $\mathrm{X}$ be the distance of the neutral axis from the edge $00^{1}$ of the belt cross-section.






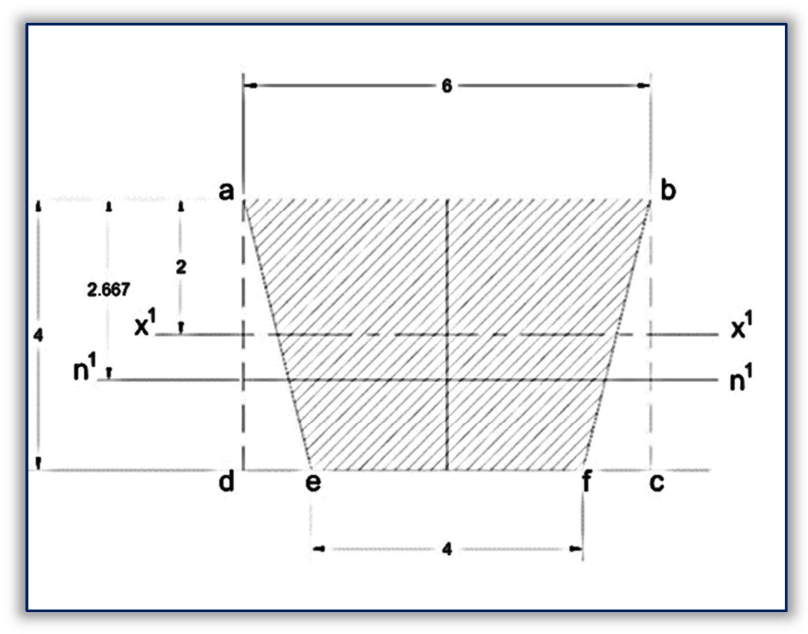

Figure 3. Cross-section Area of the V-Belt (all dimensions in mm).

$$
\begin{aligned}
& \text { Area ade }=\frac{1}{2} \times 1 \times 4=2 \mathrm{~mm}^{2} \\
& \text { Area bcf }=\frac{1}{2} \times 1 \times 4=2 \mathrm{~mm}^{2} \\
& \text { Area bcd }=6 \times 4=24 \mathrm{~mm}^{2}
\end{aligned}
$$

Area abfe $=\frac{(6+4)}{2} \times 4=20 \mathrm{~mm}^{2}$

Taking moment of area about $00^{1}$

$$
\begin{gathered}
\text { Area abfe } \times \mathrm{x}=\left(\text { Area abcd } \times \mathrm{XX}^{1}\right)-2\left(\text { Area ade } \times \mathrm{NN}^{1}\right) \\
\qquad \begin{array}{c}
20 \times \mathrm{x}=(24 \times 2)-2(2 \times 2.667) \\
20 \times \mathrm{x}=48-10.668 \\
\mathrm{x}=1.867 \mathrm{~mm}
\end{array}
\end{gathered}
$$

Given that:

Motor Pulley diameter $=45 \mathrm{~mm}$

Machine Pulley diameter $=305 \mathrm{~mm}$ and as the top face of the belt are flush with the periphery of each pulley, the corresponding pitch diameter will be given by:

$$
\begin{aligned}
& \text { Motor Pulley Pitch diameter }=45-(2 \times 1.867) \\
& \quad=41.266 \mathrm{~mm} \\
& \text { Machine Pulley diameter }=305-(2 \times 1.867) \\
& =301.266 \mathrm{~mm}
\end{aligned}
$$

The center distance of the Pulleys, which is variable to allow for tensioning, is approximately $420 \mathrm{~mm}$. The machine (wheel) pulley speed is obtained is as follows: (3 4) reference.

Machine pulley speed $=$ Motor Pulley Speed $\times$

$$
\frac{\text { diameter motor pulley }}{\text { diameter machine pulley }}
$$

$$
\begin{gathered}
\text { Machine pulley speed }=1400 \times \frac{41.266}{301.266} \\
\text { Machine pulley speed }=191.765 \mathrm{rpm}
\end{gathered}
$$

The effect of centripetal force in the belt will be small hence, it is negligible.

\subsection{The Fly Wheel}

For a flywheel four aluminum alloy density (e) is

$$
\begin{gathered}
2.8 \mathrm{mg} / \mathrm{m}=2800 \mathrm{~kg} / \mathrm{m} \\
\text { poisson's ratio }(\mathrm{v})=0.32 \\
\text { Machine pulley speed }(\mathrm{N})=191.765 \mathrm{rpm}
\end{gathered}
$$

The maximum principal stress:

$$
\begin{gathered}
\sigma=\frac{2800}{4} \frac{191.765 \times 2 x^{2}}{60} 0.68 \times 0.0125^{2}+3.32 \\
=21825.739 \mathrm{~N} / \mathrm{M}^{2}
\end{gathered}
$$

Also the maximum shear stress

$$
\begin{gathered}
\tau=\frac{2800}{4} \frac{191.765 \times 2 x^{2}}{60} 3.32 \times 0.0125^{2} \times 0.1525^{2} \\
+\left(0.68 \times 0.125^{2}\right) \\
=302.44 \mathrm{~N} / \mathrm{M}^{2}
\end{gathered}
$$

\subsection{Spring}

The spring plays the role of an absorber of the loading from the frame/ table unit thereby controlling the vibration on the machine. It also controls the effort of forces caused by the masses applied on the balancing machine.

In the design of springs, Torque developed will be equal to the product of the loading and the mean radius of the coils (Redford, 1966). The effect is similar to that produced in a shaft in torsion.

Consequently shear stress

$$
\tau=\frac{\mathrm{T} \times \mathrm{r}}{\mathrm{J}}
$$

But

$$
\frac{1}{2} \mathrm{~T} \theta=\frac{1}{2} \mathrm{WS}
$$

Where:

$\mathrm{W}=$ Axial loading on the spring

$\mathrm{D}=$ Mean diameter of coils

$\mathrm{T}=$ Torque on spring material

$\theta=$ Angle of twist

$S=$ Axial deflection of loaded end of spring

$\mathrm{d}=$ diameter of the wire

$$
\begin{aligned}
\mathrm{T} & =\frac{\mathrm{WD}}{2} \\
\frac{1}{2} \frac{\mathrm{WD}}{2} \theta & =\frac{1}{2} \mathrm{WS} \\
\theta & =\frac{2 \mathrm{~S}}{\mathrm{D}}
\end{aligned}
$$


However, for this work the spring used was purchased from the store after determining the spring index, Wahl correction factor and the true maximum shear stress:

$$
\begin{aligned}
& K=\frac{4 c-1}{4 c-4}+\frac{0.615}{c} \\
& C=\frac{D}{d}
\end{aligned}
$$
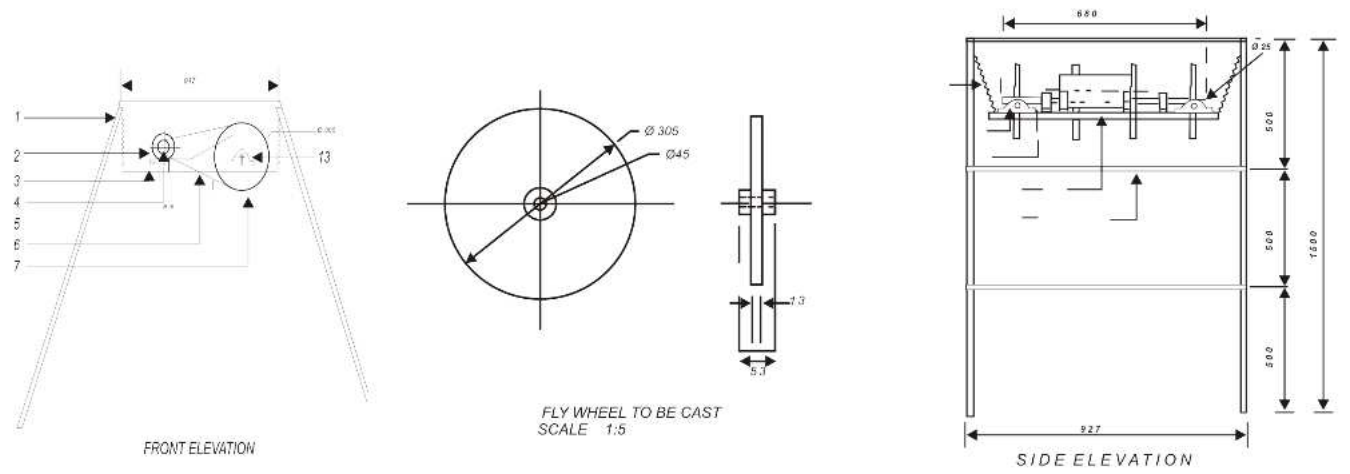

\begin{tabular}{|c|c|c|c|}
\hline Items & Descriptions & Materials & is \\
\hline 1 & 1-5 Angle Iron Stand & Mild Steel & \\
\hline 2 & Electric Motor Support & Cast lion & 2 \\
\hline 3 & 1-5 Angle Iron Frame & Mild Steel & \\
\hline 4 & Reciprocating Rod & Stainless Steel & 2 \\
\hline 5 & Connecting Rod & Mild steel & 2 \\
\hline 6 & V-Belt & Std. & $i$ \\
\hline 7 & Fly Wheet & At. Alloy & 4 \\
\hline 8 & Helical Spring & Std. & 4 \\
\hline 9 & 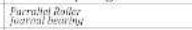 & Std. for $\varnothing 15$ & 2 \\
\hline 10 & Fly Wheel Shaft & Mild Steel & 1 \\
\hline 11 & Electric Motor & Std. & 1 \\
\hline 12 & 0.5 Flat bar Braze & Mild Steel & \\
\hline 13 & 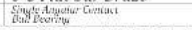 & Std. for $\varnothing 25$ & 6 \\
\hline
\end{tabular}

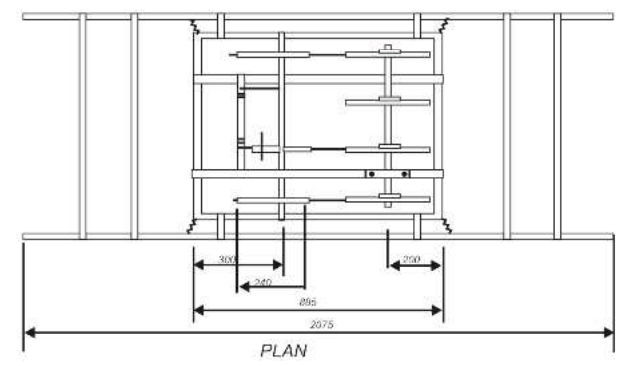

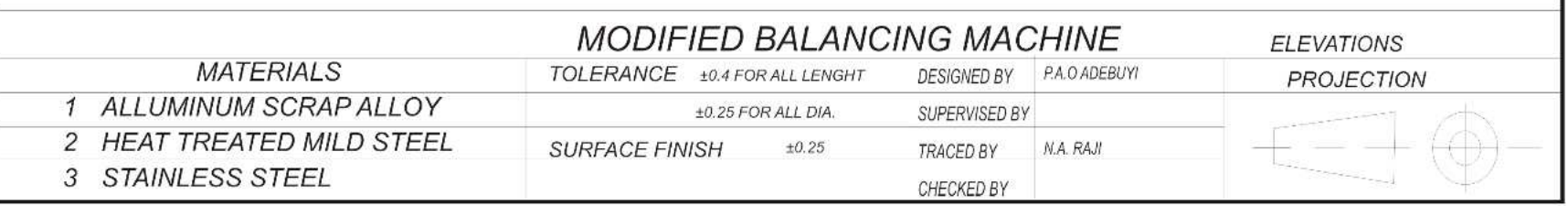

Figure 4. Assembly drawing of the balancing machine.

\section{Construction}

In constructing the equipment, consideration was given to keeping the construction costs as low as possible. Design specifications were strictly adhered to and production methods were properly reviewed to avoid repetitive work on components, which could be accomplished in one process (Lissaman. A. J 1982). Marking out was carefully done since this is often the source of many construction errors. Welding brazing and bolting were the means for fastening. Parts after the components had all be manufactured or purchased.

\subsection{Flywheel}

The flywheelsare made by casting (sand casting) using Aluminum alloy 2024- T4 (Americansoc. Metals OHIO 1981). This was chosen because it has a face centered cubic crystal structure, this is because of its ability to be deformed without fracture. The wheels are turned to give smoother surface finish. They are then bored to a $25 \mathrm{~mm}$ diameter, its flanges are chamfered $15 \times 45^{0}$, a tapered slotting- pin ways are drilled to facilitate a perfect grip on the shaft. The surface of each flywheel is indexed indicating various degree on which the suspended mass can be hung. The wheel's driver ( one of the flywheel) was machined to carry the V-belt to be connected to the motor.

\subsection{Support/Stand Unit}

This is made from a mild steel angle iron $3.8 \mathrm{~mm} \times 3.8 \mathrm{~mm}$ $\mathrm{x} 1555 \mathrm{~mm}$. there are four in numbers and are separated from one another at a distance of $927 \mathrm{~mm}$ thereby forming two distinct accessories. In each necessary, the vertical and horizontal angle irons are welded at an angle of $10^{\circ}$ as shown in the working drawing. Each accessory unit brought together at a distance $917 \mathrm{~mm}$ by brazing sideways and on top of the support unit. 


\subsection{Table / Frame Unit}

This is made of mild steel angle - iron $3.8 \mathrm{~mm} \times 3.8 \mathrm{~mm}$. Its frame like in shape with a dimension of $885 \mathrm{~mm} \times 762 \mathrm{~mm}$. The frame is attached hangers which facilitates the suspension of the frame by the springs to the support stand.

\subsection{Standard Units}

a) Spring Unit

b) Shaft Unit

c) Key and Keyways Unit

d) Reciprocating Unit

e) Power Control System Unit

\subsection{Cost Implications}

The foundation of any Engineering Design is its viability and economical use of resources to accomplish the end results. This will take account of cost of materials, cost of labour and overhead cost (Lissaman \& Martin, 1983).

Table 1. MATERIAL COST.

\begin{tabular}{|c|c|c|c|c|}
\hline $\mathbf{S} / \mathbf{N}$ & $\begin{array}{l}\text { MATERIAL } \\
\text { DESCRIPTION }\end{array}$ & $\begin{array}{l}\text { UNIT } \\
\text { PRICE }\end{array}$ & $\begin{array}{l}\text { QUANTITY } \\
\text { REQUIRED }\end{array}$ & $\begin{array}{l}\text { COST } \\
\text { (NARIA) }\end{array}$ \\
\hline 1 & Angle Bar & 135.00 & 5 & 675.00 \\
\hline 2 & Flat Steel & 200.00 & 1 & 200.00 \\
\hline 3 & Mils Steel Rod & 200.00 & 1 & 200.00 \\
\hline 4 & Circular Steel Rod & 600.00 & 1 & 600.00 \\
\hline 5 & Bearing with Flange Q25 & 100.00 & 2 & 200.00 \\
\hline 6 & $\begin{array}{l}\text { Helical Spring Q30 x } \\
\text { 350mm }\end{array}$ & 150.00 & 4 & 600.00 \\
\hline 7 & Hacksaw Blades & 40.00 & 4 & 160.00 \\
\hline 8 & $\begin{array}{l}\text { M }(11,8,5) \text { Bolts, Nuts \& } \\
\text { Washes }\end{array}$ & $10,5,5$ & $10,10,4$ & 330.00 \\
\hline 9 & Pattern (wood) & 400.00 & 1 & 400.00 \\
\hline 10 & Aluminum Alloy Casting & 450.00 & 4 & 1800.00 \\
\hline 11 & Machining of Wheel & 1200.00 & 1 & 1200.00 \\
\hline 12 & Electric Motor & 2000.00 & 1 & 2000.00 \\
\hline 13 & Electrode Gauge 12 & 500.00 & $1 \mathrm{pkt}$ & 500.00 \\
\hline 14 & Switch Box & $\begin{array}{l}130.00 \\
\text { Total Ma }\end{array}$ & $\begin{array}{l}1 \\
\text { rials Cost }\end{array}$ & $\begin{array}{l}130.00 \\
8995.00\end{array}$ \\
\hline
\end{tabular}

\subsubsection{Labour Cost}

With all the material provided, Labour cost for a week was calculated at $\$ 500.00$

\subsubsection{Overhead Cost}

This is the aggregate of indirect material cost, indirect wages and indirect expenses. The absorption rate used for estimating overhead for this project is $40 \%$ of the total cost of material and labour.

$$
40 \% \times \mathrm{N} 8995=\mathrm{N} 3598
$$



\section{Conclusions}

Frequently, a machine already in operation will need rebalancing or a new machine when assembled at its permanent location will need balancing furthermore in most cases the cost of disassembly shipping to a balancing machine are prohibitive hence the design and construction of the balancing machine was undertaken to facilitate the conduct of related experiments on vibration caused by unbalanced rotors in LASU'S Engineering Mechanics of Machine laboratory. The cost of importing a machine is far beyond the reach of the Faculty thus using locally available materials, the objectives of looking inwards has been realized.

\section{References}

[1] Douglas M and Stade/boker D. G (1963) Balancing of rotating machinery shock and vibration handbooks migracohill Bogle New York.

[2] Lissaman A. J and Martin S. J. (1983) Principle of engineering production Elbs London.

[3] McQueavy D. E. (1973) understanding balancing machines. American machinist special report 656 New York.

[4] Oviawe M. I. (1980) Studies of Rotary Engines for Automobile HND project 35780 Yaba college of Technology.

[5] Redford G. D (1966) Mechanical Engineering Design an introduction Macmillan Publishers London.

[6] Reinging K. D \&Desroechers A. A. (1986 -88) Disturbance Accommodating controllers for rotating mechanical systems. Transaction of the ASME- journal of Dynamic systems, measurement \& control Vol 108-110(1986-1988).

[7] Ryder G. H (1986) Strength of material Macmillan Publishers London.

[8] Shigley, J. E and Vicker, J J. (1980) "Theory of Machines and Mechanisms" McGraw Hill Inc.

[9] Thearle, E. L and Scheuetady, N. Y., (1994) "Dynamic Balancing of Rotating Machinery in the Field" ASME Transactions vol 56.

[10] Baumeister, T et. al (1988) Marks Standard Handbook of Mechanical Engineers. McGraw Hill company New York. 